\title{
Common Goods Emerging? On Job and Time Sharing with the Help of ICT
}

\author{
Manfred Füllsack \\ University of Graz, Austria
}

\begin{abstract}
The paper presents a proposal to allocate income opportunities and time resources among similar qualified workers with the help of an internet and smart-phone application called "Job Sharing Doodle". It builds on the assumption that tools of this kind might reduce transaction costs and therewith help to overcome typical Common Goods dilemmas which seem to impede the emergence of non-contributory income maintenance systems.
\end{abstract}

\section{Introduction}

European income maintenance systems can be distinguished in respect to the share of noncontributory benefits they foresee in the case of unemployment. Whereas in countries like France or Germany premium-based insurance systems prevail over non-contributory benefits, Scandinavian countries rather tend towards tax-based redistribution systems with less emphasis on insurance [16], [22], [24]. Theoretically, insurances can be conceived as distributing labor incomes individually on a timeline - that is, from a period in ones private life with employment to another period without employment whereas non-contributory transfer systems distribute labor incomes socially among society members - that is, from people with employment to people without. Arguments for the merits of the one or the other system are manifold and discussions fill libraries. In times of dissolving standard employment relations and growing uncertainty in regard to labor curricula and careers, non-contributory benefits seem to gain reason. With rising numbers of unemployed school leavers or single women who are looking after their children and therewith fall out of the reach of insurances, a social redistribution of economic output seems to be a safer option in terms of income maintenance.

Social redistribution, however, is subject to a typical problem which is characteristic for Common Goods [18]. By guaranteeing income irrespective of employment, such systems are prone to free riding. At least some beneficiaries might not care for employment if they can make a living on welfare. The problem thereby is not so much the lone free rider on its own [17]. Rich societies might well endure a certain percentage of "non-contributors"i without severe economic slump. As game-theoretic experiments Glance/Huberman [11], [12], Fehr/Gächter [8], [9] show, the problem rather seems to accumulate with the ones that might follow. The free riding of some discourages the contribution of others and therewith induces a downward spiral which eventually destroys the Common Good. In other words, the possibility to free ride exposes socially redistributing security systems to a countercurrent which impairs their political attractiveness.

Unfortunately, free-riding is hard to prevent. Even in highly controlled systems with severe punishments for non-contribution a certain percentage of free riding always remained (for an illustrative insider-account of the Soviet workobligation-system for instance see: Sinowjew [20]). The problem is tenacious and in practice often entails a self-accentuating dynamic of bureaucratic control which eats up means the welfare system then misses for redistribution.

But what if attempts to solve this Common Goods dilemma do not address the free riders but the community of potential contributors who are discouraged from contribution? Could they be made willing to contribute even so they are feeding free riders? Are there incentives to make them accept a (sort of) non-reciprocated welfare system even so they themselves face relative high income security? The following considerations build on the assumption that a flexibility of labor arrangements which allows respecting individual labor propensities could provide such incentives. In other words, the assumption is that a growing part of employees whose labor performances currently often are hogtied by standardized contracts with sometimes severe overtime obligations might be willing to "trade" a part of their incomes for the chance to take time-off (or a sort of "sabbaticals") every now and then. In order to effectuate these incentives, however, conventional methods malfunction. Personnel offices and labor administrations as we know them usually are not able to cope with individual (and sometimes daily changing) labor propensities. To these days, labor flexibility runs up on transaction costs too high to handle. Recently, however, information and communication technologies (ICT) seem to allow for dramatic reductions in transaction costs in many fields [19]. This paper presents some theoretical considerations on, and investigations into possibilities of flexibilizing labor organization with the help of ICT. It introduces an internet and/or 
smart-phone application tentatively called "Job Sharing Doodle" wii wich intends to facilitate a periodical exchange of income opportunities against (leisure) time in specific labor segments.

It has to be admitted though, that the scope of this tool's applicability is limited, for there are various unsolved difficulties with job sharing [3], [4], [7]. However, the conception might be helpful in fathoming the phase space for the flexibilization of labor arrangements with the help of ICT. At the least, it might trigger discussions on how future societies could cope with the organization of labor and its uncertainties.

\section{The real Tragedy of the Commons}

Basically, a socially redistributing welfare system can seem unacceptable for three interconnected reasons: 1 . it simply can seem too expensive to the ones paying for it, 2. it can seem unfair if others are not contributing to cover its costs. And 3. it can seem unnecessary if the current employment situation is satisfying and does not seem to be under risk of changes.

The second point, free riding, is a well known problem in so called social dilemmas [2], that is, in situations in which individual and social benefits differ and individuals cannot easily be precluded from misusing or exploiting social achievements. ${ }^{\text {iii }} \mathrm{A}$ common example for this dilemma is the so called Common Goods-game in which non-contribution is individually profitable as long as it remains a minority behavior. ${ }^{\text {iv }}$ If the game is repeated, however, chances are high that the profits of the minority induces majority to follow and therewith to destroy its effects. In the end, non-contribution (“defection”) does not profit anybody, but behavior stays firmly put at the sub-optimal Nash-equilibrium. Nobody is willing to contribute because nobody else is willing either. The real "Tragedy of the Commons" [15], thus, is its self-accentuating dynamic.

In order to mediate a first notion about the direction of the solution that the aforementioned conception focuses on, it might be helpful to picture this problem in the way Natalie Glance and Bernado Huberman suggested [11], [12].

According to them, the dynamics of a social dilemma when repeated can be pictured as the behavior of a ball on a rugged surface with valleys and peaks. Initially the ball is placed on a random point that corresponds to a tentative first round of the Common Goods-game. In this first round, most players invest but some decide to free ride. With repetition, the probability of free riding increases. The ball on the surface follows gravity and rolls to a valley, a local minimum that marks overall zeroinvestment. Nobody gains from investing as long as nobody else invests. The ball stays put in the valley. (Figure 1).

This minimum, however, is suboptimal. If the majority would invest they could profit more from the game. So obviously, there is a second minimum on the surface which marks a more efficient outcome and can be regarded a global minimum. Unfortunately, between this global and the local minimum there is a high mountain of pretty unstable constellations consisting of different investments which all seem to push the dynamics towards the suboptimal equilibrium.
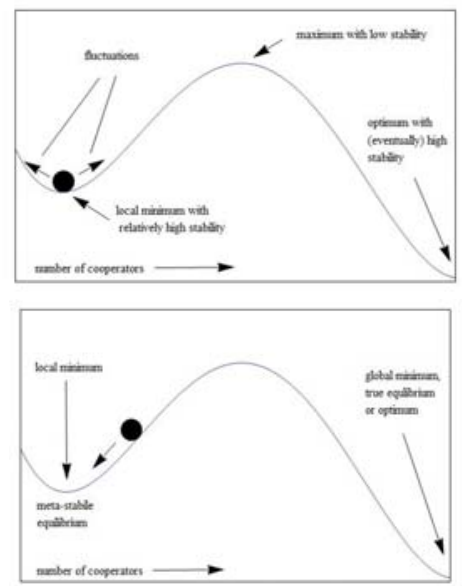

Figure 1. Dynamics of the repeated Common Goods-game, pictured as a ball on a surface with two equilibrium solutions (minima) separated by a mountain (a maximum) of instable investment constellations. Since the solution to the social dilemma at the local minimum is suboptimal, there might be fluctuations in the position of the ball (lower picture). If the frequency of fluctuations increases they might become large enough to eventually push the ball over the maximum on to the global minimum marking the optimal solution.

At the local minimum, however, nobody profits. It therefore seems likely that with time all players sooner or later should become aware of its suboptimality. Unsatisfied with what they have, they might start tentative search actions. They might deviate temporarily from zero-investment, initially of course falling back to it every time they are ratted again. But if attempts are numerous and driven by additional incentives, probability might rise that the mountain behind which the optimal solution is hidden eventually can be overcome.

The behavior of the ball in this picture gives reason to assume that the frequency of experiences with income uncertainties influences the acceptance of socially distributing welfare systems. Many of today's labor arrangements, however, shield employees with standard labor contracts from such experiences. These employees simply never or too rarely experience social redistribution as a benefit. On the one hand, this is of course fine for them. One 
would not want to expose employees to the risk of unemployment to make them contributive. On the other hand, from the perspective of precariously employed or unemployed, this shielding of some is an obstacle for solidarity with the situation of others.

The question thus arises, whether the frequency of respective income experiences can be raised without exposing the regularly employed to any risk and still give them incentives to consider social redistribution as useful. The proposed answer is to let them benefit from this redistribution as well by providing opportunities to take paid time-offs in respect to individual labor propensities. The afore mentioned Job Sharing Doodle is supposed to fathom the possibility space for this provision by facilitating and disburdening the organization of otherwise rather complex sharing and exchange processes. ${ }^{\mathrm{v}}$

\section{The working principle of the Job Sharing Doodle}

The Job Sharing Doodle is an internet based smart-phone application under development ${ }^{\mathrm{vi}}$ which intends to facilitate the allocation of income opportunities and leisure time among small or middle-sized work teams with comparable qualifications and similar labor requirements in respect to actual (e.g. daily changing) individual labor propensities. In other words, in deploying ICT, the tool aims at an efficient way to coordinate people who want to share workloads. Its precondition is a community in which some members prefer leisure time over part of their income and others have (leisure) time and would exchange it for income. ${ }^{\text {vii }}$ Or in more details, in which some would like to reduce their workloads even for waiving part of their income but are restricted by the limitations of organizational and administrative capacities which in their turn lead to inflexible labor agreements, restrictive contracts, overtime obligations etc. And in which others are systematically excluded from income opportunities by information deficits and respective organizational limitations. In order to overcome organizational limitations via calculative, communicative and networking power, the Job Sharing Doodle foresees a kind of Walrasian auction, a tâtonnement-process, in the course of which participants gradually approach an acceptable "price" for either being able to work and obtain income or to abstain from work but still obtain income in the form of the "price" for "selling" income opportunities to others. The "moral principle" of this auctioned exchange orients on the concept of tradable quotas as it currently among others is deployed in $\mathrm{CO}_{2}$-emission-trade [6], [21].

In the 1990ies this concept has been suggested for the labor market by Bert Hamminga [14]. In his "thought experiment", Hamminga considered income opportunities as a common property to which society members originally are equally entitled. This entitlement manifests in the form of so called Labor Rights which are distributed in equal amounts once in a given period (e.g. once a year) to all able-bodied members of a society in correspondence to the number of conventional income opportunities (that is, jobs) that currently exist in this society. If there is less opportunities than demand, Labor Rights are distributed in respective proportion. People who are willing to work in the given period therefore will need to stock up their share of Labor Rights by buying the missing Labor Rights from society members who are willing to sell. Those willing to sell, however, will sell only if the price of Labor rights allows them to make a living from selling. The price for Labor Rights in Hamminga's conception therefore, should form in respect to supply and demand for Labor Rights and therewith reflect the aggregated values that this society is ready to ascribe to income opportunities on the one hand and to (leisure) time on the other. ${ }^{\text {vii }}$ The price that is paid for a Labor Right then can be considered a compensation for waiving ones entitlement to an income opportunity - or alternatively, as seen from a more conventional perspective, as a socially distributed welfare benefit.

Thought-provoking as it is, the proposal, however, does not seem to be applicable to real labor conditions. Additionally to problems Hamminga mentioned himself [14], the suggested Labor Rights trade would probably soon run up on the incompatibility of actual jobs and labor requirements. Lower qualified workers might sell Labor Rights much more readily than demanded experts and therewith increase demand in their sectors, influence wages and eventually cause inflation. Nonetheless, the idea of trading income opportunities for time seems intriguing. One might want to look for a bypass for the problem of incompatible labor requirements. The Job Sharing Doodle suggests such a bypass via downscaling the (virtual) Labor Right-trade to small or middle-sized labor teams whose qualifications and actual job performances do not differ too much to be shareable $^{\mathrm{ix}}$, and to replace the (then missing) price building mechanism of the market by the tâtonnement of a Walrasian auction.

\section{The Job Sharing Doodle}

In the following, in order to explain the working principle of the Job Sharing Doodle, I will construct an example situation, using simplified figures that abstract from most difficulties actual tax and social security regulations pose. A more realistic example based on data from Austrian labor statistics can be retrieved from my webpage ${ }^{x}$. The cornerstone of both examples is a situation with more people able to perform a certain kind of work than can be paid at 
the current moment (that is, a situation with less vacancies than able-bodied people). Imagine a team of five people and an employer who for instance due to short orders suddenly can pay only four. One team member has to quit and there is no qualitative criteria about who is to go. Instead of just dismissing this member, the team decides to reallocate the remaining income opportunities with the help of the Job Sharing Doodle.

A first condition for this concerns the financial means to be reallocated. Of course, one might argue that a proposal for a new kind of organizing social welfare should include some fundamental changes in social distribution which also involves the means of the employer. On the other hand, causing additional costs to the employer might raise the complexity and severely impairs the acceptability of the conception. So for the time being, the payroll sum which the employer can afford is thought to be fixed. Team members share only conventionally available means. In this example, the costs of one fulltime employee per year are assumed to be Euro 40.000. If the employer can afford, say, Euro 160.000.- per year, he could employ four fulltime workers for this money. If this sum is to be distributed among five people, several details have to be considered. The first concerns the legal status of these five employees. If like foreseen in the conception - labor and leisure shall be allocated with utmost flexibility, be it even daily, all employees should have equal formal status. To register each of them ex post, that is after the actual decision whether to work or not in the given period has been made, might pose unacceptable administrative costs. So, formally employing them all necessitates to separate a certain percentage for “indirect labor costs" - let's say 25\% - which employers spend for taxes, for workstation equipment, working clothes etc. and - in some countries like Austria - as a contribution to the social security insurance of the employed. So if these five people shall be employed formally, in order to get the sum which actually can be distributed as gross income, 25\% have to be subtracted from the Euro 160.000.- - $^{\mathrm{x}}$, leaving Euro 120.000.-, which are available for distribution per year. In this example, the employees share monthly ${ }^{\text {xii }}$, so that the actual sum for distribution per month is Euro 10.000.--

At this point, the aforementioned Labor Right scheme comes in, which is effectuated in the form of a virtual online-auction via Internet or mobile phones. This raises the question about the minimum bid from which the auction shall start. As can be easily imagined, an auction for incomes and leisure might take a pretty long time if starting out from zero and keeping bid increments rather small for not missing an acceptable distribution. The patience of participants might not suffice. For this reason, it seems necessary that, as a further precondition, the five employees agree on a minimum bid higher than zero beforehand. However, the question as to why and how team members should agree on this bid is not so easy to answer, for it implies a sum which those team members who are willing to work have to discount from their incomes. Or in other words, this sum can be considered as an initial orientation for the gross minimum income for abstaining from work, i.e. for "virtually" selling one's Labor Rights. ${ }^{\text {xiii }}$ If conditions are favorable (which means that there is no striking disproportion of available means and number of team members), this income should not sink dramatically below the agreed-upon sum in the course of the auction.

The question as to why participants shall agree on this sum, thus, is central to the conception and to the emergence of the Common Good of income maintenance. I will therefore discuss it separately in details in section V. For the moment - in order to further explain the working principle of the Doodle I simply presuppose that the employees agree on this sum, let's say on a starting bid of Euro 800.- which in a straight-forward distribution (that is, without auctioning) would yield a monthly gross income of Euro 2300.- for each of the four team members working in the current month (i.e. for those who buy Labor Rights) and a (sort of) "non-contributory benefit" of Euro 800.- for the one team member waiving the right to work (i.e. for the one who sells Labor Rights). ${ }^{\text {xiv }}$ (Obviously, without Labor Right scheme, that is, without income for the team member not working, the working income would amount to Euro 2500.-.) The Euro 800.- and the Euro 2300.then are netted by social insurance rates ${ }^{\mathrm{xv}}$ and taxes and displayed as initial income suggestions for work and not-work to the users of the Job Sharing Doodle.

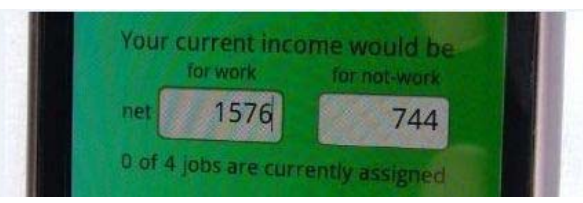

Figure 3. Clipping of the auction page of the Job-Sharing Doodle with initial net income suggestions for work and for abstaining from work ("not-work", i.e. for selling ones Labor Rights). Figures correspond to a version of the example at the webpage indicated in footnote 11 .

\section{The Auction}

At this point, the auction can start in order to determine the final amounts of incomes. At certain times - be it for example in the beginning of the year, the month or in the morning of the working day participants are asked - for instance by an alert on their smart phones - to convene on the internet. On a mask - either in their browser or on their smart phone - they can retrieve information about their situation, first of all on the calculated net income suggestions for work and not-work corresponding to the number 
of members of their team and to the number of available (affordable) jobs (see Figure3).

In addition, users can retrieve graphic information about the opportunity space of their distribution in the form of a plot indicating the incomes corresponding to the starting sum.



Figure 4. Graphic representation of the work and not-work income correlation. The upper green line indicates net work-incomes in correspondence to the respective net not-work income indicated by the lower green line. Red lines indicate gross correlations.

The main part, however, is a possibility to indicate ones willingness either to work or not to work in respect to initial income suggestions. At the moment, I experiment with a scrollbar and a <transmit>button in the following outlay.



When the auction starts, participants are asked to indicate and transmit their current preferences. These indications then are weighted by the Doodle. To keep it simple ${ }^{\mathrm{xvi}}$, indicating $<$ work $>$ weighs twice as much as indicating $<$ may be $>$, with $<$ no way $>$ and $<$ rather not $>$ respectively. From the input of all participants, the Doodle then determines a tendency whether there might be too little team members willing to work (i.e. not all vacancies might be filled) or, on the opposite, there will be enough or too many. According to this tendency, it either increments the income for work by an adjustable amount (for example Euro 10) if there is too little work-willing participants, or it increments the income suggestion for not-work, if there is too many. The respective mirror-income (that is the income for not-work if work incomes are incremented and for work if notwork incomes are incremented) is decremented correspondingly. Incrementing and decrementing thereby is calculated so that the checksum of income suggestions always corresponds to the overall available means. In other words, the system necessitates no additional means. The resulting sums, netted by social insurance and taxes ${ }^{\text {xvi }}$ then are presented to the user as new income suggestions. If one of the participants should be happy with one of the suggestions, she can accept it by pushing either an <accept work >-button or an <accept notwork $>$-button. If accepted, the position (work or notwork) and the respective income are booked for this user. She and her income is out of the auction. The Doodle subtracts this income from the distributable sum, calculates incomes anew and suggests them again to the users. If nobody agrees, it again increments either the work income if there is too many work-averse participants or it increments the not-work income if there is too few of them. It proceeds in this way until all available vacancies or all available positions for not-work are booked. ${ }^{\text {xviii }}$



Figure 6. Clipping of the auction page of the Job-Sharing Doodle.

If one kind of positions is booked out finally, the Doodle just divides the remaining means equally. That is, if there is still work positions to be filled, means are divided as work income and if it's notwork positions that have to be filled means are considered a compensation for waiving ones right to work. Alternatively, the remaining means could be divided along the mean of the incomes of those participants who accepted work or not-work early on in the auction. Leftovers could then be used in later auctions to compensate for discrepancies if they arise.

In experiments conducted so far, however, - see below -, the difference of incomes accepted and incomes assigned at the end of an auction never was so dramatic to necessitate this administratively rather costly step. At least with computer-generated agents, the system generates a rather balanced distribution of incomes that nevertheless accounts for and corresponds to individual preferences within the given possibility space.

In order to put the operability of the Job Sharing Doodle to some initial tests, so far various simulation methods have been employed. At first a MultiAgent-model has been implemented with Netlogo (Willensky 1999). In it, a population of (computer generated) agents was made to trade income opportunities in the aforementioned way. The agents were endowed with a propensity to work in the form 
of a randomly generated number between 0 and 99 . Their decisions to indicate one of the four preferences or to accept work or not-work were calculated in respect to the level of work or not-work incomes and in respect to another random number which was used to make the decisions stochastic. An agent for example indicating < rather not $>$ in the first round of the auction, changed her choice to $<$ no way> in the next round when the not-work income was higher than the agreed upon initial income suggestion and a randomly chosen number between 0 and 99 was larger than her propensity to work. This agent finally accepted <not-work>, if 1.) the positions for not-work were not yet fully occupied, 2.) the current level of not-work income was still higher than the initial income suggestion and 3.) a new random number between 0 and 99 was larger than her propensity to work. (no agent was allowed to jump more than one decision-step per round of auction).

With the above mentioned figures, and also with figures taken from Austrian labor statistics, the simulation generates a range of work and not-work incomes which in my opinion does not seem unacceptable, given the high amount of choice and income certainty that comes with it. (for detailed figures see Füllsack 2011).

\section{6. (Some) problems and summary}

Admittedly, there is a couple of problems and one central question that need to be answered for the tool to be useful. Some rather technical problems - as for example the possibility of unacceptable long auction runs, the possibility of deploying "strategies" in order to try to influence incomes by indicating untrue preferences, and, above all, the limits of applicability due to highly specialized qualifications and labor requirements - I have discussed in Füllsack 2011.

The central problem addressed in this paper concerns a precondition for the use of this tool that I mentioned in section III. This is the problem which circles around the question on the minimum bid of the auction. As said before, when simply starting from zero and keeping bid increments small for not missing an acceptable distribution, the auction might take a long time to generate an acceptable Labor Right price. With low patience of the participants, the starting bid could pre-demarcate a rather low and small corridor for the final sum which participants get for selling their Labor Rights. For this reason, it seems necessary to preset a starting bid higher than zero. But this brings up the aforementioned question as to how and why participants should agree on such a starting bid if this implies that their labor incomes will be reduced by a part of it.
True, conceptually, these shares are considered a compensation for waiving ones right to work, that is, for selling Labor Rights. In practice, however, a right to work - though legally stipulated in some constitutions - is difficult to enforce. Chances seem high, that the foreseen income for not-work will be regarded as a sort of unreciprocated payment, may be even an unconditional Basic Income (White [25], Van Donselaar [23]). The problem thus might translate into the question as to why participants should voluntarily agree on lower incomes for themselves to supply others with an income for idling?

The answer to this question, as suggested in this paper, becomes apparent if the income maintenance which tools like the Job Sharing Doodle promise is conceived in terms of a Common Good. In regard to contemporary labor market developments on the one hand and to the administrative restrictions for individually flexibilizing ones working life on the other hand (that is, for arranging ones working life more in respect to labor propensities) the workless income implied by the conception seems beneficiary to all. However, the road that leads to it is paved with individual incentives for not contributing. And, as experiments with repeated Common Good-games show, the abstention of just one team member from contribution can lead to cascades of non-contribution by others. The question about the agreement on the starting bid therefore, is central to the conception's implications on the possibility of income maintenance.

But as suggested in section II, the impact on the participants' behavior might work in the opposite direction as well. By providing respective incentives and increasing the frequency of decisions whether to contribute or not (in this case, whether to agree on a starting bid higher than zero), the probability for leaving the local minimum of overall defection (that is the Nash-equilibrium of not being ready to convene on a high enough starting bid because nobody else is ready either) can rise. These incentives together with the frequency of decisions therefore are the Archimedean points at which the Job Sharing Doodle aims.

The Doodle tries to effectuate these incentives by helping to reduce transaction costs for finding agreement. In its current form ${ }^{\text {xix }}$, it foresees a possibility to determine the starting sum via an input window to which users are asked to make respective suggestions before the auction starts. The tool then calculates the mean from these suggestions and takes it as the factual starting bid as long as the majority of the participants is not ready to contribute, that is, as long as the majority indicates zero as suggested starting bid. From the moment the majority starts to suggest sums higher than zero, the median of their suggestions is taken in order to further stimulate their investment. Admittedly, at the time being we do not 
have experimental confirmation whether this method works as proposed. But, - respective experiments anticipating - it might be hypothesized that a proceeding of this form is apt to confront participants repeatedly with the question of how much an acceptable sum for waiving ones right to work could be. It would confront them as often as they want to share work. In other words, the Doodle involves employees with this question by facilitating a relatively high frequency of reallocating labor and leisure. It lets them experience the promise of income maintenance on their own. Or in again other words, it puts the chance of paid time-offs into the reach of employees who currently face labor arrangements too restrictive to allow for anything else than daily work.

With this involvement, the chances for the Common Good of societal income maintenance seem to get reconfigured. Employees who just once more had to decide for unsatisfying labor because overall contribution to non-contributory welfare was low, might start tentative "search actions". And the more often they face a decision, the more their "search actions" might gain momentum and eventually, may be, drive their will to contribute over the "tipping point" of unlikely constellations towards the global optimum of overall contribution. Tools like the Job Sharing Doodle therewith might help to enhance and firmly establish Common Goods as the one of a noncontributory social benefit system.

\section{References}

[1] Ashby, Ross (1956) Introduction to Cybernetics. London. Chapman and Hall.

[2] Barry, Brian / Hardin, Russell (Eds.). (1982): Rational Man and Irrational Society? Beverly Hills, CA: Sage.

[3] Boyle, Adrienne (ed.) (1980): Job sharing. A study of the costs, benefits and employment rights of job sharers. London: Equal Opportunities Commission.

[4] Calmfors, Lars / Hoel, Michael (1989): Work Sharing, Employment and Shiftwork; in: Oxford Economic Papers, New Series, Vol. 41, No. 4 (Oct., 1989), pp. 758-773.

[5] Coase, Ronald: (1937): The Nature of the Firm; in: Economica 4/1937, 16, p. 386-405.

[6] Dales, John H. (1968): Pollution, Property and Prices. An Essay on Policy-Making in Economics. Toronto: Toronto University Press.
[7] Dreze, Jacques (1991): Work-Sharing. Some Theory and Recent European Experience; in: Economic Policy 3, p. 562-619.

[8] Fehr, Ernst / Gächter, Simon (2000): Cooperation and Punishment in Public Goods Experiments; in: American Economic Review 90, p. 980.

[9] Fehr, Ernst / Gächter, Simon (2002): Altruistic Punishment in Humans, Nature 415, 137-140.

[10] Füllsack, Manfred (2011): Basic Income from the bottom up. Allocating jobs and incomes with the "Job Sharing Doodle"; in: Basic Income Studies Vol. 6, 1/2011, DOI: 10.2202/1932-0183.1175

[11] Glance, Natalie S. / Huberman, Bernado A. (1993): The Outbreak of Cooperation, Journal of Mathematical Sociology Vol 17(4), 281-302.

[12] Glance, Natalie S. / Huberman, Bernado A. (1994): The Dynamics of Social Dilemmas; in: Scientific American March 1994, p. 76-81.

[13] Groot, Lucas F.M. (1999): Basic income and Unemployment. Utrecht (Thela-Thesis).

[14] Hamminga, Bert (1995): Demoralizing the Labour Market: Could Jobs be like Cars and Concerts?; in: Journal of Political Philosophy, 3/1995, p. 23-35.

[15] Hardin, Garrett (1968): The Tragedy of the Commons; in: Science 162, 1243-1248.

[16] Millar, Jane, (ed.), 2009. Understanding Social Security: Issues for Policy and Practice. 2nd edition. Bristol: Policy Press.

[17] Moffitt, Robert (1992): Incentive Effects of the U.S. Welfare System: A review. Journal of Economic Literature vol. 30, 1 (March 1992), pp. 1-61.

[18] Olson, Mancur Jr. (1965): The Logic of Collective Action: Public Goods and the Theory of Goods.. Cambridge Massachusetts, Harvard University Press.

[19] Shirky, Clay (2008): Here comes Everybody. The Power of Organizing without Organizations. London. Penguin.

[20] Sinowjew, Alexander (1982): Homo Soveticus. Zürich (Diogenes)

[21] Tietenberg, Tom H. (2006): Emissions Trading: Principles and Practice. 2nd ed. Washington, DC, Resources for the Future. 
[22] Titmuss, Richard M. (1968): The Relationship between Social Security Programs and Social Service Benefits: An Overview, Commitment to Welfare. London: Allen and Unwin.

[23] Van Donselaar, Gijs (2009) , The Right to Exploit, Parasitism, Scarcity, and Basic Income, Oxford University Press.

[24] Walker, Robert (2004): Social Security and Welfare: Concepts and Comparisons (Introducing Social Policy). Buckingham, Open University Press.

[25] White, S. (1997), Liberal Equality, Exploitation, and the Case for an Unconditional Basic Income, Political Studies, XLV, 312-326.

[26] Williamson, Oliver E. (1975): Markets and Hierarchies: Analysis and Antitrust Implications. A Study in the Economics of Internal Organization. New York. The Free Press.

\section{Endnotes}

\footnotetext{
${ }^{\mathrm{i}}$ I use quotes here to indicate the problem of defining what a valuable ("productive" etc.) contribution exactly is in modern societies. Although not further discussed in this paper, I consider this question central to the debates on social security in regard to labor arrangements. See: Füllsack 2011.

ii The term Doodle derives from a popular internet tool by the Swiss information technician Michael Näf which helps to coordinate dates and meetings by providing a mask for pre-delimitating possible dates. An online-version can be accessed at: http://www.doodle.com/main.html?locale=en

iii These achievements are said to have the feature of non-excludability from consumption, meaning that users cannot, with justifiable costs, be kept from consuming. Doing so, entails a control system which tends to get complex in the course of controlling [1].

iv Consider the following situation: three people get 20 Euros each with the invitation to invest all or a part or nothing of it into a common pool. Whatever sum will be in the pool after investment will be doubled and distributed equally among the players. If all players for example invest 20 Euros, each of them gets a final pay-off of 40 Euros. However, if one player invests, say, just 5 Euros, while the others still invest 20, the outcome is different. In the pool will be 45 Euros. Doubled this will be 90 which provides each of the players with 30 Euros. For the two 20Euro-investors this is their final pay-off. For the 5Euro-investor however, the 30 Euros add up to 45 with the 15 he didn't invest, which is definitely
}

higher than the 40 he might have received when investing all of his money.

$v$ The complexity of these interactions entails what subsequently to Ronald Coase has been called "transaction costs" and is responsible for rather hierarchical, centralistic attempts to cope with. May be most basically, its consequences can be pictured by the so called "Metcalf's Law" which states that a cooperation of $n$ people takes $(n * n-1) / 2$ interactions (if each of the $n$ people should interact just once with everybody else). While $n$ grows arithmetically, interactions, and therewith "transaction costs", grow exponentially.

vi Simulators - a Java-Applet and an application for Android smart-phones - can be retrieved from: http://homepage.univie.ac.at/manfred.fuellsack/jsd/e n/category/sims/java_sim/ [Accessed: March 19th 2012]

vii In some respects this seems to apply to the employment situation in many OECD-countries. For a recent study on time-use and respective capacities in Austria cf.: http://www.statistik.at/web_de/statistiken/soziales/ze itverwendung/index.html [Accessed: 19 January 2011]

viii Of course, this highly theoretical conception is conditioned to the assumption that supply and demand can take effect without any distortions by path dependencies, lock-ins and similar feedback effects.

ix Examples would be teams of medical staff in hospitals for instance whose actual labor schedules sometimes already are organized with the help of ICT. Cf. among others the project at: http://www.gpnetworks.co.uk/?r=site/demo

[Accessed: 19 January 2011] Other examples are airline staff, waiters in gastronomy, all kinds of chauffeurs, nursing auxiliaries for elderly people etc.

$x \quad$ See: http://homepage.univie.ac.at/manfred.fuellsack/jsd/e n/anwendungsbeispiele/ [Accessed: March 19th 2012]

xi If "indirect labor costs" would be discounted beforehand unequally, that is, in respect to an anticipated amount of labor each of the participants assumes to be willing to perform, they will not be able to change their minds later on. So even if their might be a slight injustice in dividing "indirect labor costs” equally, it benefits flexibility.

xii For calculations it is no problem to share weekly or daily or in whatever period the job reasonably allows.

xiii The sum therefore equals the Labor Right price times the proportional share of Labor Rights each of the participants is entitled to.

xiv The calculation is straight forward and works with any number of people and affordable positions: the gross income for not working (800.-) times the 
number of team members for which no vacancy exists (in this example just one) is subtracted from the distributable sum (10.000.-) and the result is divided by the number of available positions (in this example four).

${ }^{\mathrm{xv}}$ It could be argued here, that with the Labor Right system in place and working all or a part of the payments for unemployment insurance could be dumped, since people might no longer depend on additional security. For the time being however, these payments are included in the calculations in order to provide compatibility to the current system.

xvi Experiments with more complex weighting procedures showed no effects that justified their costs.

xvii Due to the progressive taxation in Austria, the Doodle calculates with gross values which are turned to net when presented to the user.

xviii Of course, if among five people there is only one possibility for not-working, the auction might be over quite fast. If the work that needs to be done depends on full capacity utilization there is little to do about this. In the short run, the only thing that might prevent notorious "lazies" to accept any notwork income immediately, is the relatively low income they might obtain in this way. In the long run however, in a team which distributes income opportunities on a regular base, one might think about an accumulating right to overrule the choices of others when having not obtained ones choice for several rounds. If capacity utilization is more flexible, it might also be possible to allow more notworking positions than necessitated by the financial situation. True, the participants deciding for work then face larger workloads, but their income would be significantly higher as well. The sum available for their income would be divided by less people. In order to account for this possibility, and in order to allow as much choice and freedom as possible in respect to consuming time, the current version of the Doodle-simulator (see endnote vi) foresees a possibility to regulate a percental deflection from the available positions for not-work. Admittedly, this might be an issue which needs an agreement with the employer.

xix Which in this aspect differs slightly from the versions currently displayed as simulators. 